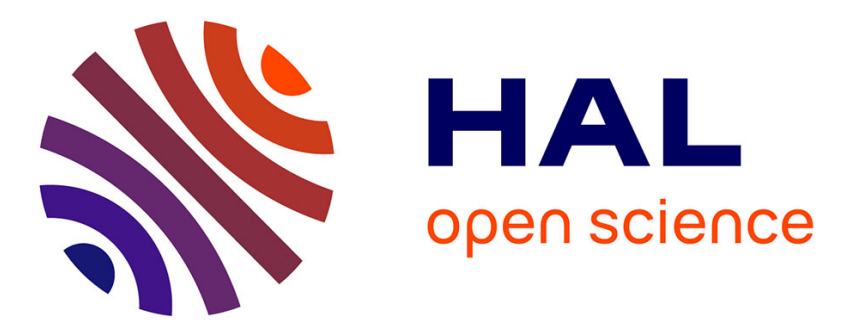

\title{
Spectroscopic properties of Tm:Bi4Ge3O12 crystals grown by the micro-pulling-down method
}

Wen Lu, Jie Xu, Qingsong Song, Kaiting Bian, Jun Guo, Jian Liu, Dongzhen Li, Peng Liu, Chaojin Zhang, Xiaodong Xu, et al.

\section{To cite this version:}

Wen Lu, Jie Xu, Qingsong Song, Kaiting Bian, Jun Guo, et al.. Spectroscopic properties of Tm:Bi4Ge3O12 crystals grown by the micro-pulling-down method. Journal of Luminescence, 2021, 238, pp.118199. 10.1016/j.jlumin.2021.118199 . hal-03324128

\section{HAL Id: hal-03324128 \\ https://hal.science/hal-03324128}

Submitted on 8 Nov 2021

HAL is a multi-disciplinary open access archive for the deposit and dissemination of scientific research documents, whether they are published or not. The documents may come from teaching and research institutions in France or abroad, or from public or private research centers.
L'archive ouverte pluridisciplinaire HAL, est destinée au dépôt et à la diffusion de documents scientifiques de niveau recherche, publiés ou non, émanant des établissements d'enseignement et de recherche français ou étrangers, des laboratoires publics ou privés. 


\title{
Spectroscopic properties of $\mathrm{Tm}: \mathrm{Bi}_{4} \mathrm{Ge}_{3} \mathrm{O}_{12}$ crystals grown by the micro-pulling-down method
}

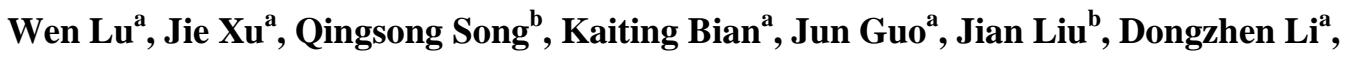 \\ Peng Liu ${ }^{a}$, Chaojin Zhang ${ }^{a}$, Xiaodong $\mathrm{Xu}^{\mathrm{a}, *}$, Jun $\mathrm{Xu}^{\mathrm{b} \text {,* }}$, Kheirreddine Lebbou ${ }^{\mathrm{c} \text {,* }}$
}

a Jiangsu Key Laboratory of Advanced Laser Materials and Devices, School of Physics and Electronic Engineering, Jiangsu Normal University, Xuzhou 221116, China

b School of Physics Science and Engineering, Institute for Advanced Study, Tongji University, Shanghai 200092, China

c Institut Lumière Matière, UMR5306 Université Lyon1-CNRS, Université de Lyon, Lyon 69622, Villeurbanne Cedex, France

Corresponding author:

Email address: xdxu79@jsnu.edu.cn (X.Xu), xujun@mail.shcnc.ac.cn (J. Xu),

kheirreddine.lebbou@univ-lyon1.fr (K. Lebbou)

\begin{abstract}
$\mathrm{Tm}^{3+}$-doped bismuth germanate crystals (Tm:BGO) with various doping concentrations of 0.5 , $0.75,1.0,1.5$, and 2.0 at.\% were grown by the micro-pulling-down method $(\mu-\mathrm{PD})$. The effect of thulium concentration on the growth, structure, absorption spectra, emission spectra and fluorescence lifetime of ${ }^{3} \mathrm{H}_{4}$ and ${ }^{3} \mathrm{~F}_{4}$ state was studied. Under excitation of $792 \mathrm{~nm}$, Tm:BGO crystals exhibit two fluorescence bands corresponding to the ${ }^{3} \mathrm{H}_{4} \rightarrow{ }^{3} \mathrm{~F}_{4}$ and the ${ }^{3} \mathrm{~F}_{4} \rightarrow{ }^{3} \mathrm{H}_{6}$ transitions. The fluorescence lifetime of ${ }^{3} \mathrm{H}_{4}$ state decreased strongly as the thulium concentration increased, while the lifetime of ${ }^{3} \mathrm{~F}_{4}$ state are relatively constant for all thulium concentrations.
\end{abstract}

Keywords: $\mathrm{Tm}: \mathrm{Bi}_{4} \mathrm{Ge}_{3} \mathrm{O}_{12}$, Micro-pulling-down method, Spectroscopic property 


\section{Introduction}

$\mathrm{Tm}^{3+}$-doped laser materials have attracted much attention due to their potential applications in medical surgery, tele-communication, remote sensing, and pumping sources of optical parametric oscillators [1-3]. During the last decade, different Tm doped crystalline host materials have been investigated for their favourable properties to obtain an efficient laser emission. $\mathrm{Tm}^{3+}$ ions can be efficiently excited by commercial AlGaAs laser diode around $800 \mathrm{~nm}\left(\mathrm{Tm}^{3+},{ }^{3} \mathrm{H}_{6} \rightarrow{ }^{3} \mathrm{H}_{4}\right.$ transition) and emission spectral intervals are around $1.5 \mu \mathrm{m}$ [4], $1.9 \mu \mathrm{m}$ [5] and $2.3 \mu \mathrm{m}$ [6]. Laser oscillation of $\mathrm{Tm}^{3+}$ has been demonstration in numerous hosts such as $\mathrm{LiYF}_{4}$ [7,8], $\mathrm{BaY}_{2} \mathrm{~F}_{8}$ [9], $\mathrm{CaF}_{2}$ [10], $\mathrm{MgWO}_{4}$ [11], $\mathrm{CaGdAlO}_{4}$ [12], $\mathrm{YAlO}_{3}$ [13], $\mathrm{LuScO}_{3}$ [14], and $\mathrm{Y}_{2} \mathrm{O}_{3}$ [15].

Bismuth germanate crystal $\mathrm{Bi}_{4} \mathrm{Ge}_{3} \mathrm{O}_{12}$ (BGO) belongs to cubic system with the space group of I43d [16]. It has been studied as a host for $\mathrm{Er}^{3+}, \mathrm{Eu}^{3+}, \mathrm{Dy}^{3+}, \mathrm{Pr}^{3+}$ and $\mathrm{Nd}^{3+}$ ions, etc., with applications as optical temperature sensors, scintillators and laser gain media [17-21]. In addition,

as a host material, BGO possesses many qualities desirable for laser applications such as excellent physical and chemical properties [22]. In 1979, A.A. Kaminskii et al. reported the absorption and emission properties of $\mathrm{Tm}^{3+}$-doped BGO crystal grown by Czochralski method [23]. The micro-pulling-down ( $\mu$-PD) method was used to grow BGO crystals with high quality and transparency, where the crystals have low thermal strain compared to other growth methods [24-26]. Eu:BGO and Nd:BGO crystals have also been grown by the $\mu$-PD method [27-29]. BGO melt congruently and relatively high rate of evaporation of $\mathrm{Bi}_{2} \mathrm{O}_{3}$ occurs during melt overheating [30-31].

In this work, Tm:BGO crystals with different doping concentration were successfully grown by the micro-pulling down method. Achievement of stationary conditions for the growth of uniformly shaped (constant diameter) fiber crystals was considered as final goal and positive outcome of this paper. Spectral properties of the crystals were studied at room temperature.

\section{Experimental}

\subsection{Crystal growth}

Tm: $\mathrm{Bi}_{4} \mathrm{Ge}_{3} \mathrm{O}_{12}$ crystals were grown by the $\mu$-PD method [32]. The $\mathrm{Tm}_{2} \mathrm{O}_{3}$ (99.999\%), $\mathrm{Bi}_{2} \mathrm{O}_{3}$ (99.999\%) and $\mathrm{GeO}_{2}$ (99.999\%) powders were used as starting materials and weighed according to the formula $\mathrm{Tm}_{4 \mathrm{x}} \mathrm{Bi}_{4(1-\mathrm{x})} \mathrm{Ge}_{3} \mathrm{O}_{12}(\mathrm{x}=0.005,0.0075,0.01,0.015,0.02)$. After thoroughly mixed in an agate mortar, they were pressed into bulks and sintered in the air at $750^{\circ} \mathrm{C}$ for $24 \mathrm{~h}$. The polycrystalline Tm:BGO was melted in a platinum crucible, and then the melt was pulled down through a capillary channel at the bottom of the crucible. The Tm:BGO crystals were grown with constant pulling rate of $0.3 \mathrm{~mm} / \mathrm{min}$ by pulling down a $\langle 210\rangle$ oriented BGO seed in the air atmosphere. Whatever the starting composition prepared in this work $(\mathrm{Tm} \leqslant 2 \mathrm{at} \%)$, we had not seen any evolution of growth Kinetic. As shown in Fig. 1(a)-(e), five crack-free Tm:BGO single 
crystals with dimensions of $\Phi 2 \times 44-68 \mathrm{~mm}^{3}$ were obtained and present a light yellow color. The crystals produced from the crucibles were very uniform in shape according to the measurements performed directly from the the fibers with accuracy of about $\pm 20 \mu \mathrm{m}$. The crystals have a rough appearance on the outside, but the inner part of the crystals was transparent and free of visible defects. It is important to note that, once the melt becomes Bi-poor there is no way to establish constant properties (solidification temperature and following shape of the meniscus) of the melt Thus, for all Ge-rich systems evaporation of the bismuth oxide will only increase dissolution of the melt and its transformation from melt to flux system.
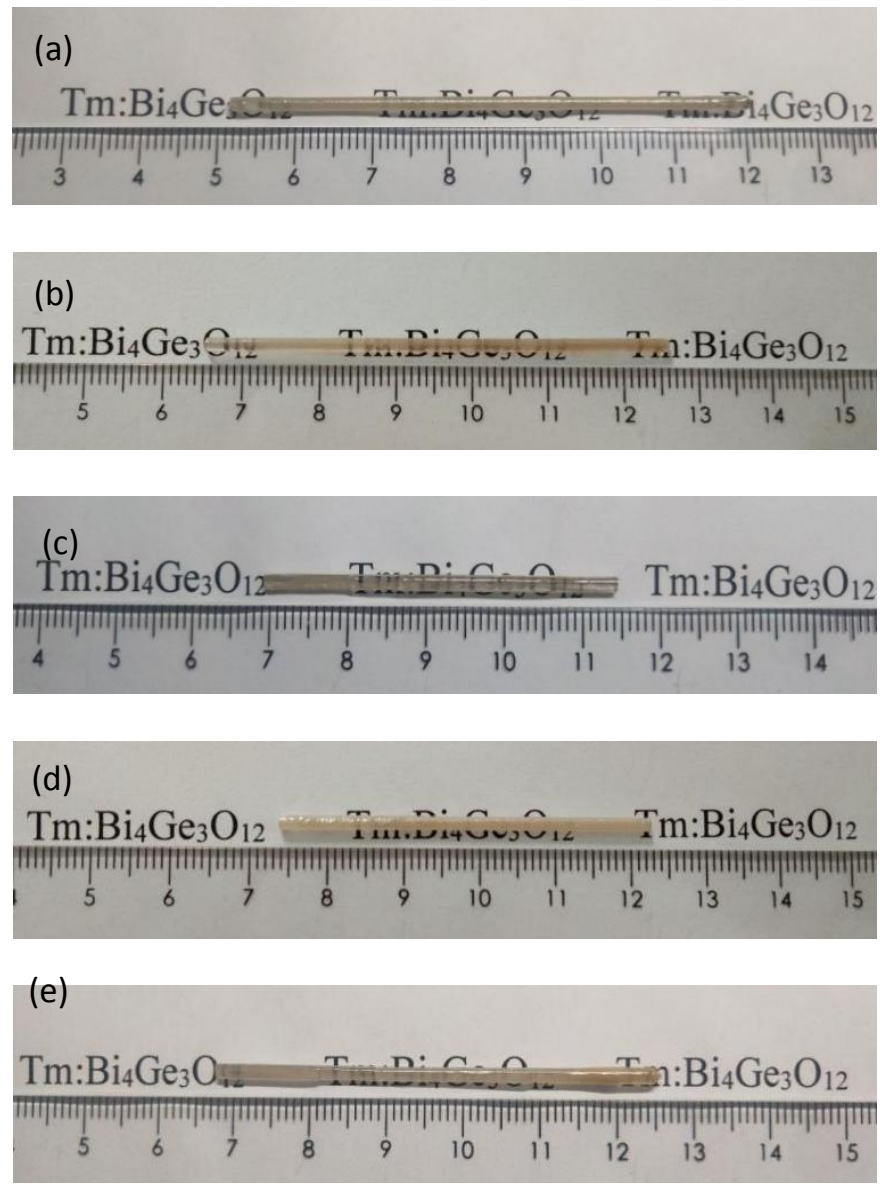

Fig.1. Photographs of the as-grown Tm:BGO crystals, (a) 0.5 at. $\%$, (b) 0.75 at. $\%$, (c) 1.0 at. $\%$, (d) 1.5 at. $\%$ and (e) 2.0 at.\%.

\section{$2.2 \mathrm{X}$-ray powder diffraction}

In order to investigate the structure of Tm:BGO crystals, small section of the samples were cut from the as-grown crystals and grounded into powder in an agate mortar. And then the structure was examined by X-ray diffraction method (XRD, Bruker-D2, Germany) at a scan width of $0.05^{\circ}$ with a range $5^{\circ}-90^{\circ}$.

\subsection{Spectra measurements}

For spectroscopic measurements, the Tm:BGO samples were cut from the as-grown crystals 
and then optically polished to flat and parallel faces with the size of $\Phi 2 \times 2 \mathrm{~mm}^{3}$. The absorption spectra were measured from 400 to $2000 \mathrm{~nm}$ by a UV-VIS-NIR spectrophotometer (Lambda 1050, Perkins Elmer, U.S.A.) at room temperature. The fluorescence spectrum as well as the decay time were recorded by a fluorescence spectrometer (Edinburg Instrument, FLS1000, U.K.) under the excitation $792 \mathrm{~nm}$. All the measurements were carried out at room temperature.

\section{Results and discussion}

\subsection{Crystal structure}

The room temperature XRD patterns of Tm:BGO crystals are shown in Fig. 2. The crystal structure of undoped and Tm-doped BGO belongs to the cubic space group I $43 \mathrm{~d}$. The diffraction peaks of Tm:BGO crystals are in agreement with JCPDS 84-0505 of $\mathrm{Bi}_{4} \mathrm{Ge}_{3} \mathrm{O}_{12}$. No additional impurity phases were found in the patterns. Due to the different doping concentration of $\mathrm{Tm}^{3+}$ ions, the relative intensity of each diffraction peak is different and the diffraction peaks of the XRD patterns were slightly offset to the right compared to the JCPDS 84-0505 of BGO. The lattice constants of Tm:BGO crystals are listed in Table 1. With the increasing of doping concentration $\mathrm{x}$, the calculated lattice constant decreased, which is attributed to the smaller radius of $\mathrm{Tm}^{3+}$ ion $(0.869 \AA)$ compared with that of $\mathrm{Bi}^{3+}$ ion $(0.96 \AA)$ [33]. The results reveal that a small amount of $\mathrm{Tm}^{3+}$ ions did not change the structure of BGO crystal without any composition evolution resulting in a second-phase formation.

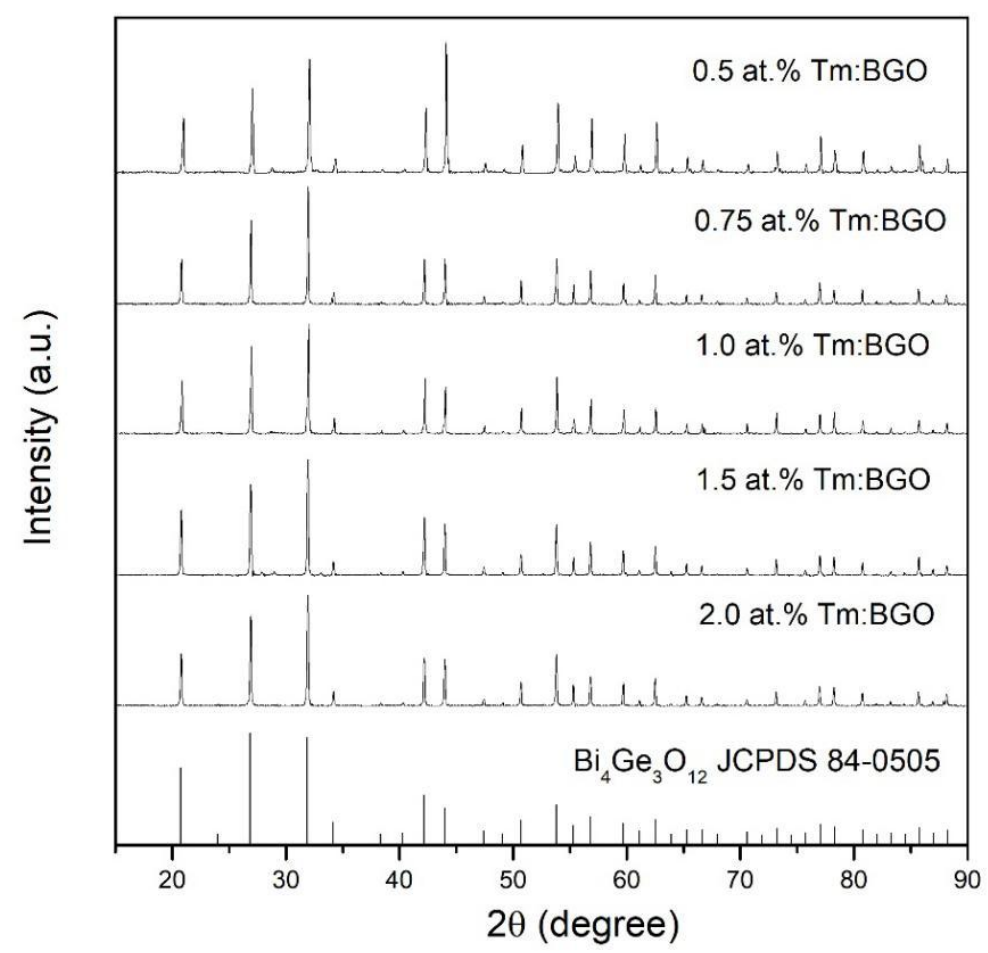

Fig.2. Room temperature XRD patterns of Tm:BGO crystals with a standard reference of undoped BGO (JCPD 84-0505) 
Table 1. Lattice parameters of Tm:BGO crystals as a function of Tm concentration

\begin{tabular}{cc}
\hline $\mathrm{x}$ at.\% Tm:BGO & $\mathrm{a}(\AA)$ \\
\hline 0 & $10.497^{[34]}$ \\
0.5 & 10.453 \\
0.75 & 10.451 \\
1.0 & 10.445 \\
1.5 & 10.428 \\
2.0 & 10.419 \\
\hline
\end{tabular}

\subsection{Absorption spectra}

The room temperature absorption spectra of BGO crystals doped with $0.5,0.75,1.0,1.5$, and 2.0 at. $\%$ of $\mathrm{Tm}^{3+}$ ions in the wavelength region of $400-2000 \mathrm{~nm}$ are displayed in Fig. 3. We note that all the samples have the same absorption spectra. Five absorption bands are located at approximately 474, 680, 792, 1211 and $1737 \mathrm{~nm}$, which are attributed to the transitions from the ${ }^{3} \mathrm{H}_{6}$ ground state to ${ }^{1} \mathrm{G}_{4},{ }^{3} \mathrm{~F}_{2}+{ }^{3} \mathrm{~F}_{3},{ }^{3} \mathrm{H}_{4},{ }^{3} \mathrm{H}_{5}$ and ${ }^{3} \mathrm{~F}_{4}$ excited states, respectively. Among five main peaks, the peak at $792 \mathrm{~nm}\left({ }^{3} \mathrm{H}_{6} \rightarrow{ }^{3} \mathrm{H}_{4}\right)$ matches well with the emission of the commercial AlGaAs LD pumping. As the doping concentration increases from 0.5 at. $\%$ to 2.0 at. $\%$, the absorption coefficient at $792 \mathrm{~nm}$ increases from $0.17 \mathrm{~cm}^{-1}$ to $0.62 \mathrm{~cm}^{-1}$. For 2.0 at. $\%$ Tm:BGO crystal, the full width at half-maximum (FWHM) of the absorption band at $792 \mathrm{~nm}$ is about $3.3 \mathrm{~nm}$. The value is smaller than that of Tm:YAG (4 nm at $780 \mathrm{~nm}[35])$, but larger than that of Tm:KY ${ }_{3} \mathrm{~F}_{10}(2.8 \mathrm{~nm}$ at $778.6 \mathrm{~nm}[36])$, which is suitable for LD pumping. 


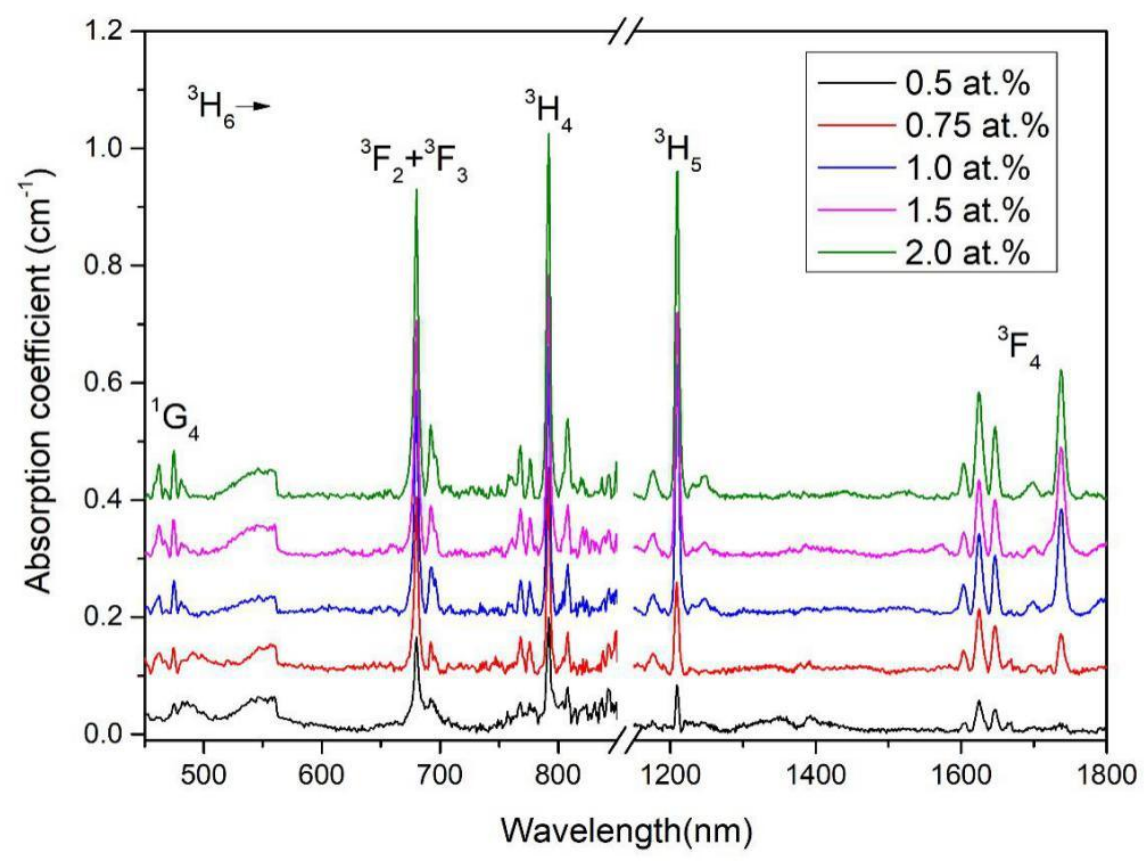

Fig.3. Absorption spectra of Tm:BGO crystals as a function of Tm concentration.

\subsection{Fluorescence spectra}

Under excitation at $792 \mathrm{~nm}$, two fluorescence bands corresponding to the ${ }^{3} \mathrm{H}_{4} \rightarrow{ }^{3} \mathrm{~F}_{4}$ and the ${ }^{3} \mathrm{~F}_{4}$ $\rightarrow{ }^{3} \mathrm{H}_{6}$ transitions within the measuring range are shown in Fig. 4. At thulium concentrations from 0.5 at. $\%$ to 2 at. $\%$, no distinct change in the shape and position of the emission bands was observed in Tm:BGO crystals. We found that the intensity of emissions of the ${ }^{3} \mathrm{~F}_{4} \rightarrow{ }^{3} \mathrm{H}_{6}$ transition increases with the increase of thulium concentration. The upper level ${ }^{3} \mathrm{~F}_{4}$ can be populated by a cross-relaxation process $\left({ }^{3} \mathrm{H}_{4}+{ }^{3} \mathrm{H}_{6} \rightarrow{ }^{3} \mathrm{~F}_{4}+{ }^{3} \mathrm{~F}_{4}\right)$ and the effectivity of this process increases with higher thulium concentrations. For 2.0 at.\% Tm:BGO crystal, the FWHM of the emission band at $1452 \mathrm{~nm}$ was calculated to be $3.9 \mathrm{~nm}$ and the FWHM of the emission band at $1879 \mathrm{~nm}$ is about $44.6 \mathrm{~nm}$. The FWHM of ${ }^{3} \mathrm{~F}_{4} \rightarrow{ }^{3} \mathrm{H}_{6}$ transition is larger than the value of Tm:YAG (31.37 nm [37]). We did not register the emission around $2.3 \mu \mathrm{m}$. The energy gap between ${ }^{3} \mathrm{H}_{4}$ and ${ }^{3} \mathrm{H}_{5}$ energy level is about $4100 \mathrm{~cm}^{-1}$ and the $\mathrm{Tm}^{3+}$ ions at the ${ }^{3} \mathrm{H}_{4}$ level can relax nonradiatively to the ${ }^{3} \mathrm{H}_{5}$ level due to the lager phonon energy $\left(\approx 900 \mathrm{~cm}^{-1}\right)$ of BGO crystal [21]. 

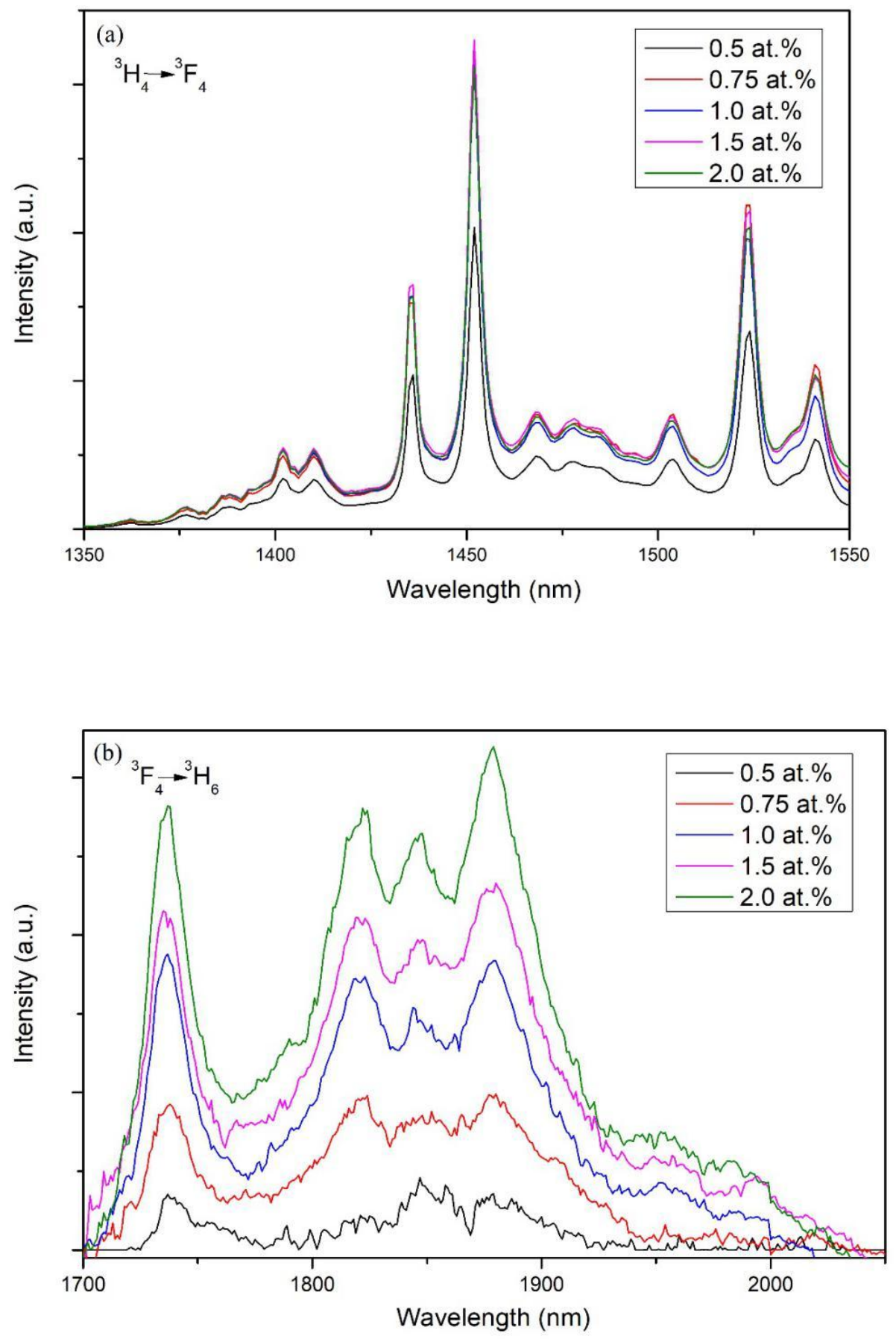

Fig.4. Fluorescence spectra of Tm:BGO crystals with different Tm doping concentration in (a) $1350-1550 \mathrm{~nm}$ and (b) $1700-2150 \mathrm{~nm}$. 


\subsection{Fluorescence lifetime}

Fig. 5(a) presents the fluorescence decay curves of Tm:BGO crystals in correspondence with the ${ }^{3} \mathrm{H}_{4} \rightarrow{ }^{3} \mathrm{~F}_{4}$ transition at $1452 \mathrm{~nm}$ at room temperature. The fluorescence lifetime was calculated to be $352 \mu \mathrm{s}, 318 \mu \mathrm{s}, 313 \mu \mathrm{s}, 267 \mu \mathrm{s}$ and $218 \mu \mathrm{s}$ for the doping concentration of $0.5,0.75,1.0,1.5$ and 2.0 at.\%, respectively, by a single exponential fitting. The lifetime of the ${ }^{3} \mathrm{H}_{4}$ state decreased strongly as the thulium concentration increased, which is due to the concentration quenching effect caused by the energy transfer between thulium ions at higher thulium concentration [38]. The fluorescence lifetime at $1452 \mathrm{~nm}$ of 1 at.\% Tm:BGO is much longer than that of $1 \%$ $\mathrm{Tm}: \mathrm{KGd}\left(\mathrm{WO}_{4}\right)_{2}\left(175 \mu \mathrm{s}\right.$ [38]) and $1 \% \mathrm{Tm}: \mathrm{YVO}_{4}(100 \mu \mathrm{s}[39])$.

The fluorescence decay curves of Tm:BGO crystals corresponding to the ${ }^{3} \mathrm{~F}_{4} \rightarrow{ }^{3} \mathrm{H}_{6}$ transition at $1879 \mathrm{~nm}$ are shown in Fig. 5(b). The measured decay curves showed a single exponential decaying behavior, and the fluorescence lifetime was measured to be 5.43, 5.16, 5.36, 5.69 and $5.64 \mathrm{~ms}$, respectively. In contrast to the lifetime of the ${ }^{3} \mathrm{H}_{4}$ state, the fluorescence lifetimes of ${ }^{3} \mathrm{~F}_{4}$ state are relatively constant for all thulium concentrations. This can be explained by two different mechanisms: the reabsorption effect between ${ }^{3} \mathrm{~F}_{4} \rightarrow{ }^{3} \mathrm{H}_{6}$ resonant transitions and repopulation of the ${ }^{3} \mathrm{H}_{4}$ state via the ${ }^{3} \mathrm{H}_{4}+{ }^{3} \mathrm{H}_{6} \rightarrow{ }^{3} \mathrm{~F}_{4}+{ }^{3} \mathrm{~F}_{4}$ cross-relaxation process [38]. The fluorescence lifetime at $1879 \mathrm{~nm}$ of 1 at.\% Tm:BGO is much longer than that of $1 \% \mathrm{Tm}: \mathrm{KGd}\left(\mathrm{WO}_{4}\right)_{2}(1.71 \mathrm{~ms}$ [38]) and $1 \% \mathrm{Tm}: \mathrm{YVO}_{4}(1.03 \mathrm{~ms}$ [39]). The results indicated that Tm:BGO single crystal may be a promising laser gain medium.

For $1.45 \mu \mathrm{m}$ emission, the lifetime of the terminal ${ }^{3} \mathrm{~F}_{4}$ level is much longer than that of the initial ${ }^{3} \mathrm{H}_{4}$ level, making the ${ }^{3} \mathrm{H}_{4} \rightarrow{ }^{3} \mathrm{~F}_{4}$ transition self-terminating. The sensitive co-doping ions like $\mathrm{Pr}^{3+}, \mathrm{Ho}^{3+}$ and $\mathrm{Tb}^{3+}$ ions were proposed to depopulate ${ }^{3} \mathrm{~F}_{4}$ state efficiently [40-42], which will be our next investigation in the near future. 

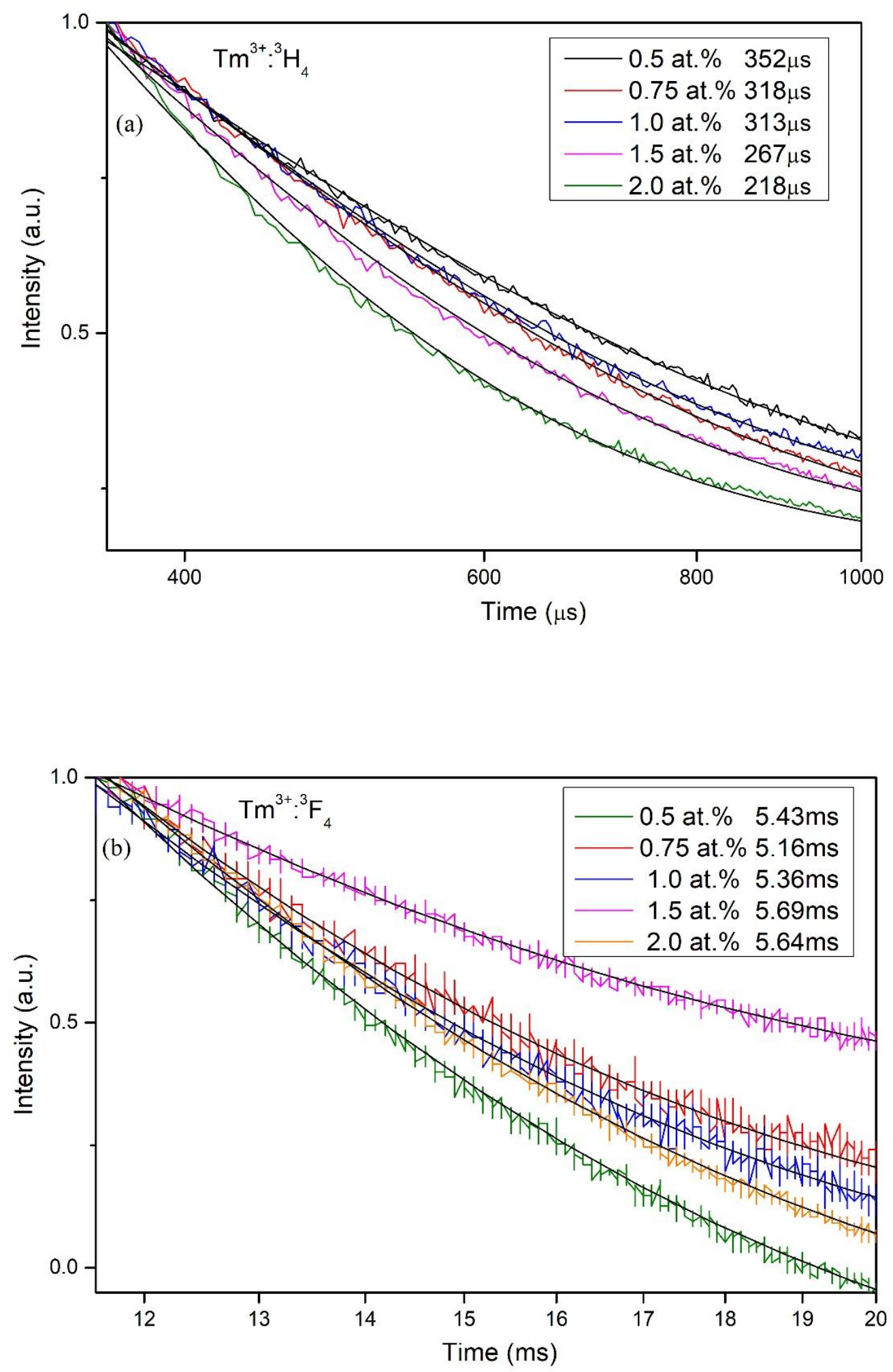

Fig.5. Fluorescence decay curves of the ${ }^{3} \mathrm{H}_{4}$ and ${ }^{3} \mathrm{~F}_{4}$ level of Tm:BGO crystals with different doping concentration. 


\section{Conclusion}

Tm-doped BGO crystals with different doping concentration were successfully grown by the $\mu$-PD method and uniformly single crystals fibers of constant diameter was reported. The room temperature XRD revealed that the cell parameter decreased with the increasing of doping concentration in good agreement with Vegard Low [43]. The absorption spectra, emission spectra and fluorescence lifetimes of Tm:BGO crystals were measured at room temperature. The absorption peak at $792 \mathrm{~nm}$ matches well with the emission of the commercial AlGaAs LD pumping. The intensity of emissions of the ${ }^{3} \mathrm{~F}_{4} \rightarrow{ }^{3} \mathrm{H}_{6}$ transition increases with the increase of thulium concentration. The fluorescence lifetime of ${ }^{3} \mathrm{H}_{4}$ state decreased strongly as the thulium concentration increased, while the lifetime of ${ }^{3} \mathrm{~F}_{4}$ state are relatively constant for all thulium concentrations. The results indicate that Tm:BGO crystal could be a promising laser gain medium.

\section{Acknowledgements}

This work is partially supported by National Natural Science Foundation of China (No.

61621001) and "Qinglan Project" of the Young and Middle-aged Academic Leader of Jiangsu

College and University.

\section{References}

[1] E.C. Honea, R.J. Beach, S.B. Sutton, J.A. Speth, S.C. Mitchell, J.A. Skidmore, M.A. Emanuel, S.A. Payne, 115-W Tm:YAG diode-pumped solid-state laser, IEEE J. Quantum Electron. 33 (1997) $1592-1600$

[2] J.J. Zayhowski, J. Harrison, C. Dill, J. Ochoa, Tm:YVO ${ }_{4}$ microchip laser, Appl. Opt. 34 (1995) $435-437$

[3] P. Zhang, X. Huang, R. Wang, Z. Li, H. Yin, S. Zhu, Z. Chen, Y. Hang, Enhanced $1.4 \mu \mathrm{m}$ emissions of $\mathrm{Tm}^{3+}$ via $\mathrm{Tb}^{3+}$ deactivation in $\left(\mathrm{Gd}_{0.5} \mathrm{Lu}_{0.5}\right)_{2} \mathrm{SiO}_{5}$ crystal, Optical Materials Express. 8 (2018) 668-675

[4] W. Ryba-Romanowski, M. Berkowski, B. Viana, P. Aschehoug, Relaxation dynamics of excited states of $\mathrm{Tm}^{3+}$ in $\mathrm{SrGdGa}_{3} \mathrm{O}_{7}$ crystals activated with $\mathrm{Tm}^{3+}$ and $\mathrm{Tm}^{3+}+\mathrm{Tb}^{3+}$, Appl. Phys. B 64 (1997) 525-529

[5] L. Zheng, J. Xu, L. Su, H. Li, W. Ryba-Romanowski, R. Lisiecki, P. Solarz, Crystal structure and optical study of Tm: $\mathrm{Sc}_{2} \mathrm{SiO}_{5}$ single crystal, Appl. Phys. Lett. 96 (2010) 121908

[6] Q. Li, J. Dong, Q. Wang, Y. Xue, H. Tang, X. Xu, J. Xu, Crystal growth, spectroscopic characteristics, and Judd-Ofelt analysis of Tm: $\mathrm{GdScO}_{3}$, Opt. Mater. 109 (2020) 110298 
[7] H. Huang, S. Wang, H. Chen, O.L. Antipov, S.S. Balabanov, D. Shen, High power simultaneous dual-wavelength $\mathrm{CW}$ and passively-Q-switched laser operation of LD pumped Tm:YLF at 1.9 and $2.3 \mu \mathrm{m}$, Opt. Express 27 (2019) 38593-38601

[8] R.C. Stoneman, L. Esterowitz, Continuous-wave 1.50- $\mu$ m thulium cascade laser, Opt. Lett. 16 (1991) 232-234

[9] A. muti, I. Baylam, M. Tonnelli, A. Sennaroglu, Tunable continuous-wave laser operation of $\mathrm{Tm}^{3+}: \mathrm{BaY}_{2} \mathrm{~F}_{8}$ near $2.3 \mu \mathrm{m}$, Opt. Lett. 45 (2020) 4104-4107

[10] R. Thouroude, A. Tyazhev, A, Hideur, P. Loiko, P. Camy, J.L. Doualan, H. Gilles, M. Laroche, Widely tunable in-band-pumped Tm: $\mathrm{CaF}_{2}$ laser, Opt. Lett. 45 (2020) 4511-4514

[11] L. Wang, W. Chen, Y. Zhao, Y. Wang, Z. Pan, H. Lin, G. Zhang, L. Zhang, Z. Lin, J.E. Bae, T.G. Park, F. Rotermund, P. Loiko, X. Mateos, M. Merom U. Griebner, V. Petrov, Single-walled carbon-nanotube saturable absorber assisted Kerr-lens mode-locked Tm: $\mathrm{MgWO}_{4}$ laser, Opt. Lett. 45 (2020) 6142-6145

[12] J. Lan, Z. Zhou, X. Guan, B. Xu, H. Xu, Z. Cai, X. Xu, D. Li, J. Xu, Passively Q-switched Tm:CaGdAlO 4 laser using a $\mathrm{Cr}^{2+}: \mathrm{ZnSe}$ saturable absorber, Opt. Mater. Express 7 (2017) 1725-1731

[13] L. Guillemot, P. Loiko, A. Braud, J.L. DOUALAN, a. Hideur, M. Koselja, R. Moncorge P. Camy, Continuous-wave Tm: $\mathrm{YAlO}_{3}$ laser at $2.3 \mu \mathrm{m}$, Opt. Lett. 44 (2019) 5077-5080

[14] X. Xu, Z. Hu, D. Li, P. Liu, J. Zhang, J. Xu, First laser oscillation of diode-pumped $\mathrm{Tm}^{3+}$-doped $\mathrm{LuScO}_{3}$ mixed sesquioxide ceramic, Opt. Express 25 (2017) 15322-15329

[15] H. Huang, H. Wang, D. Shen, VBG-locked continuous-wave and passively Q-switched Tm: $\mathrm{Y}_{2} \mathrm{O}_{3}$ ceramic laser at $2.1 \mu \mathrm{m}$, Opt. Mater. Express 7 (2017) 3147-3154

[16] S.A.S. Farias, M.V. Lalic, The local structure around the Nd impurity incorporated into the $\mathrm{Bi}_{4} \mathrm{Ge}_{3} \mathrm{O}_{12}$ crystal matrix: An ab initio study, Solid. State Commun. 150 (2010) 1241-1244

[17] B. Huang, B. Zhang, X. Qian, J. Wang, Q. Yang, L. Su, Effects of Er3+ concentration on upconversion luminescence and temperature sensing properties in $\mathrm{Bi}_{4} \mathrm{Ge}_{3} \mathrm{O}_{12}$ crystal, J. Alloys Compd. 853 (2021) 156970

[18] J.B. Shim. A. Yoshikawa, M. Nikl, A. Vedda, T. Fukuda, Radios-, photo- and thermo-luminescence characterization in $\mathrm{Eu}^{3+}$-doped $\mathrm{Bi}_{4} \mathrm{Ge}_{3} \mathrm{O}_{12}$ single crystal for scintillator application, Opt. Mater. 24 (2003) 285-289

[19] G. M. Kuzmicheva, L.I. Ivleva, I.A. Kaurova, E.V. Khramov, E.E. Dunaeva, R.D. Svetogorov, V.B. Rybakov, Local structural features and composition of the $\mathrm{Bi}_{4} \mathrm{Ge}_{3} \mathrm{O}_{12}$ :Dy ${ }^{3+}$ crystals: effect of doping concentration, CrystEngComm 22 (2020) 5666-5677

[20] A.A. Kaminskii, S.E. Sarkisov, G.A. Denisenko, V.V. Ryabchenkov, V.A. Lomonov, Yu.E. 
Perlin, M.G. Blazha, D. Schultze, B. Hermoneit, P. Reiche, Growth, spectral and luminescence study of cubic $\mathrm{Bi}_{4} \mathrm{Ge}_{3} \mathrm{O}_{12}: \mathrm{Pr}^{3+}$ crystals, Phys. Stat. Sol. A 85 (1984) 553-567

[21] A.A. Kaminskii, D. Schultze, B. Hermoneit, S.E. Sarkisov, L. Li, J. Bohm, P. Reichem R. Ehlert, A.A. Mayer, V.A. Lomonov, V.A. Balashov, Spectroscopic properties and stimulated emission in the ${ }^{4} \mathrm{~F}_{3 / 2} \rightarrow{ }^{4} \mathrm{I}_{11 / 2}$ and ${ }^{4} \mathrm{~F}_{3 / 2} \rightarrow{ }^{4} \mathrm{I}_{13 / 2}$ transitions of $\mathrm{Nd}^{3+}$ ions from cubic $\mathrm{Bi}_{4} \mathrm{Ge}_{3} \mathrm{O}_{12}$ crystals, Phys. Stat. Sol. A 33 (1976) 737-753

[22] P.A. Williams, A.H. Rose, K.S. Lee, D.C. Conrad, G.W. Day, P.D. Hale, Optical, thermo-optic, electro-optic, and photoelastic properties of bismuth germanate $\left(\mathrm{Bi}_{4} \mathrm{Ge}_{3} \mathrm{O}_{12}\right)$, Appl. Opt. 35 (1996) 3562-3569

[23] A.A. Kaminskii, S.E. Sarkisov, T.I. Butaeva, G.A. Denisenko, B. Hermoneit, J. Bohm, W. Grosskreutz, D. Schultze, Growth, spectroscopy, and stimulated emission of cubic $\mathrm{Bi}_{4} \mathrm{Ge}_{3} \mathrm{O}_{12}$ crystals doped with $\mathrm{Dy}^{3+}, \mathrm{Ho}^{3+}, \mathrm{Er}^{3+}, \mathrm{Tm}^{3+}$, or $\mathrm{Yb}^{3+}$ ions, Phys. Stat. Sol. A 56 (1979) 725-736

[24] J.B. Shim, J.H. Lee, A. Yoshikawa, M. Nikl, D.H. Yoon, T. Fukuda, Growth of $\mathrm{Bi}_{4} \mathrm{Ge}_{3} \mathrm{O}_{12}$ single crystal by the micro-pulling-down method from bismuth rich composition, J. Cryst. Growth 243 (2002) 157-163

[25] V. Chani, K. Lebbou, B. Hautefeuille, O. Tillement, and J.-M. Fourmigue,

Evaporation induced diameter control in fiber crystal growth by micro-pulling-down technique: Bi4Ge3O12, Cryst. Res. Technol. 41, No. 10, (2006) 972 - 978

[26]H Farhi, S Belkahla, K Lebbou, C Dujardin, BGO fibers growth by $\mu$-pulling down technique and study of light propagation - Physics Procedia 2 (3) (2009) 819-825

[27] N. Li, Y. Xue, D. Wang, B. Liu, C. Guo, Q. Song, X. Xu, J. Liu, D. Li, J. Xu, Z. Xu, J. Xu, Spectroscopic properties of $\mathrm{Eu} \mathrm{Bi}_{4} \mathrm{Ge}_{3} \mathrm{O}_{12}$ single crystal grown by the micro-pulling down method, J. Lumin. 208 (2019) 208-212

[28] N. Li, Y. Xue, D. Wang, B. Liu, C. Guo, Q. Song, X. Xu, J. Liu, D. Li, J. Xu, Z. Xu, J. Xu, Optical properties of $\mathrm{Nd}: \mathrm{Bi}_{4} \mathrm{Ge}_{3} \mathrm{O}_{12}$ crystals grown by the micro-pulling down method, J. Lumin. 206 (2019) 412-416

[29] J.B. Shim, A. Yoshikawa, M. Nikl, T. Fukuda, $\mathrm{Eu}^{3+}$ doped $\mathrm{Bi}_{4} \mathrm{Ge}_{3} \mathrm{O}_{12}$ fiber crystals grown by the by the micro-pulling down method, J. Cryst. Growth 245 (2002) 67-72

[30] A.B. Kaplun and A.B. Meshalkin, J.Cryst.Growth, 167 (1996) 171.

[31] V.I. Chani, K. Lebbou， Evaporation Induced Diameter Control Growth

Book, Advances in Materials Research, Shaped Crystal Growth by Micro-Pulling-Down Technique, edited by T.Fukuda and V.Chani, Springer-Verlag (2007) 115- 127

[ 32] J. Xu, Q. Song, J. Liu, S. Zhou, Y. Pan, D. Li, P. Liu, X. Xu, Y. Ding, J. Xu, K. Lebbou, 
Spectroscopic characteristics of $\mathrm{Dy}^{3+}$-doped $\mathrm{Y}_{3} \mathrm{Al}_{5} \mathrm{O} 12$ (YAG) and $\mathrm{Y}_{3} \mathrm{ScAl}_{4} \mathrm{O}_{12}$ (YSAG) garnet single crystals grown by the micro-pulling-down method, J. Lumin. 215 (2019) 116675

[33] R.D.Shannon, C.T.Prewit, Acta Crystallog.B25 (1969) 925

[34] P. Fischer, F. Waldner, Cubic crystal structure of piezoelectric Bi4Y3O12 ( $Y=\mathrm{Ge}, \mathrm{Si})$, Solid State Commum. 44 (1982) 657-661

[35] T.Y. Fan, G. Huber, R.L. Byer, P. Mitzscherkich, Spectroscopy and diode laser-pumped operation of Tm, Ho:YAG, IEEE J. Quantum Electron. 24 (1998) 924-933

[36] P. Loiko, J.L. Doualan, L. Guillemot, R. Moncorge, F. Starecki, A. Benayad, E. Dunina, A. Kornienkom L. Fomicheva, A. Braud, P. Camy, Emission properties of $\mathrm{Tm}^{3+}$-doped $\mathrm{CaF}_{2}$, $\mathrm{KY}_{3} \mathrm{~F}_{10}, \mathrm{LiYF}_{4}, \mathrm{LiLuF}_{4}$ and $\mathrm{BaY}_{2} \mathrm{~F}_{8}$ crystals at $1.5 \mu \mathrm{m}$ and $2.3 \mu \mathrm{m}$, J. Lumin. 225 (2020) 117279

[37] B.J. Fei, J.Q. Huang, W. Guo. Q.F. Huang, J. Chen. F. Tang, W.C. Wang, Y.G. Cao, Spectroscopic properties and laser performance of Tm:YAG ceramics, J. Lumin. 142 (2013) 189-195

[38] F. Güell, J. Gavaldà, R. Solé, M. Aguiló, F. Díaz, M. Galan, J. Massons, 1.48 and 1.84 m thulium emissions in monoclinic $\mathrm{KGd}\left(\mathrm{WO}_{4}\right)_{2}$ single crystals, J. Appl. Phys. 95 (2004) 919-923

[39] F.S. Ermeneux, C. Goutaudier, R. Moncorgé, M.T. Cohen-Adad, M. Bettinelli, E. Cavalli, Growth and fluorescence properties of $\mathrm{Tm}^{3+}$ doped $\mathrm{YVO}_{4}$ and $\mathrm{Y}_{2} \mathrm{O}_{3}$ single crystals, Opt. Mater. 8 (1997) 83-90

[40] Z. Mazurak, M. Czaja, R. Lisiecki, J. Gabrys'-Pisarska, Optical properties of the $\mathrm{Tm}^{3+}$ and energy transfer between $\mathrm{Tm}^{3+} \rightarrow \mathrm{Pr}^{3+}$ ions in $\mathrm{P}_{2} \mathrm{O}_{5}-\mathrm{CaO}-\mathrm{SrO}-\mathrm{BaO}$ phosphate glass, Opt. Mater. 33 (2011) 506-510

[41] R. C. Stoneman, L. Esterowitz, Continuous-wave 1.50- $\mu$ m thulium cascade laser, Opt. Lett. 16 (1991) 232-234

[42]Q. Li, J. Dong, Q. Wang, Y. Zhao, Y. Xue, H. Tang, X. Xu, J. Xu, Growth and spectroscopic properties of $\mathrm{Tm}^{3+}$ and $\mathrm{Tb}^{3+}$ co-doped $\mathrm{GdScO}_{3}$ crystal, J. Lumin. 230 (2020) 117681

[43] L. Vegard, Z. Phys. 517 (1921);Z. Kristallogr. 67, 239 (1928)] 